\title{
Resting metabolic rate, fat-free mass and catecholamine excretion during weight loss in female obese patients
}

\author{
R. Menozzi, M. Bondi, A. Baldini, M. G. Venneri, A. Velardo and G. Del Rio* \\ Centro di Nutrizione Clinica e Malattie Metaboliche, Dipartimento di Medicina Interna, Università di Modena, \\ Via del Pozzo, 71 - Policlinico, 41100 Modena, Italy
}

(Received 8 February 1999 - Revised 15 December 1999 - Accepted 24 January 2000)

\begin{abstract}
The reduction in resting metabolic rate (RMR) during weight loss exceeds that accounted for by changes in body composition by $15 \%$, suggesting that factors other than fat-free mass (FFM) explain the metabolic adaptation during food restriction in obesity. Our study aimed to establish if changes in the sympathoadrenal system activity, as inferred from an integrated measure such as $24 \mathrm{~h}$ urinary excretion of catecholamines, may play a role in the RMR adaptation observed during dietary restriction in obese patients. Ninety-three obese female subjects consumed a low-energy $\operatorname{diet}(\mathrm{LED})(2930 \mathrm{~kJ} / \mathrm{d}(700 \mathrm{kcal} / \mathrm{d}))$ for a 3-week period. At the beginning and at the end of the study, $24 \mathrm{~h}$ urinary excretion of catecholamines, FFM and RMR were measured. The LED induced a significant reduction in body weight $(-3.3$ (SEM 0.4) $\mathrm{kg} ; P<0.01$ ), FFM $(-1.9$ (SEM $0.7) \mathrm{kg} ; P<0.01)$ and in the fat mass $(-1.2$ (SEM 0.5$) \mathrm{kg} ; P<0.01)$. Noradrenalin excretion $(24 \mathrm{~h})$ decreased during the LED from 264 (SEM 26) during a weight-maintenance period to 171 (SEM 19) nmol/24 h after consumption of the LED for 3 weeks $(P<0 \cdot 001)$; mean $24 \mathrm{~h}$ adrenalin excretion did not change during the LED (22 (SEM 3) during the weight-maintenance period $v .21$ (SEM 3 ) nmol/24 h after consumption of the LED for 3 weeks; NS). The LED induced a significant decrease in RMR (7300 (SEM 218) v. 6831 (SEM 138) kJ/24 h; $P<0.001$ ). The only independent variable that significantly explained variations in RMR both before and after consumption of the LED for 3 weeks, was FFM ( $r^{2} 0.79$ and $r^{2} 0.80$ respectively). Urinary noradrenalin excretion explained a further $4 \%$ of the variability in RMR, but only before the diet, so that a role of sympathoadrenal system on RMR seems to be present in obese patients in basal conditions but not at the end of the LED.
\end{abstract}

\section{Resting metabolic rate: Fat-free mass: Catecholamines: Low-energy diet}

Resting metabolic rate (RMR) accounts for about 50-70\% of total daily energy expenditure $(\mathrm{EE})$ and represents the cost of processes such as the maintenance of transmembrane ion gradients and resting cardiopulmonary activity (Ravussin $\&$ Bogardus, 1992). As a consequence, fat-free mass (FFM) together with total body weight, age and sex account for about $80 \%$ of the variance in RMR (Ravussin \& Bogardus, 1992).

It has also been demonstrated that RMR displays a familial aggregation, thus suggesting that variance in RMR may be determined, at least in part, by genetic influences (Bogardus et al. 1986; Bouchard et al. 1989).

The thermic effect of feeding, which is the energy required for the digestion, transport and deposition of nutrients, accounts for about $10 \%$ of total $24 \mathrm{~h}$ EE while nonresting EE, i.e. all the remaining energy consumption, which mainly occurs in the form of physical activity, represents about $30 \%$ of daily EE.

As obesity stems from an imbalance between energy intake and $\mathrm{EE}$, it has been proposed that a low $24 \mathrm{~h} \mathrm{EE}$ predisposes to weight gain (Ravussin et al. 1988). RMR in obese subjects is low when expressed per kg body mass, but it is normal if FFM is accounted for; this suggests that alterations in EE components other than RMR, such as diet-induced thermogenesis, may be important in the development of obesity (Webber et al. 1994).

Several studies in animals have shown that the sympathoadrenal system plays an important role in determining daily EE (Bray et al. 1989). The infusion of small amounts of adrenalin (A) into healthy human subjects stimulates thermogenesis, increases heart rate and respiratory frequency; moreover, it has been shown that plasma A levels for stimulating

\footnotetext{
Abbreviations: A, adrenalin; EE, energy expenditure; FFM, fat-free mass; FM, fat mass; LED, low-energy diet; NA, noradrenalin; RMR, resting metabolic rate; SNS, sympathetic nervous system.

* Corresponding author: Dr Graziano Del Rio, fax +39 059 363114, email delrio@unimo.it
} 
thermogenesis are well within the physiological range (Webber \& Macdonald, 1993). $\beta$-Adrenoceptor blockade reduces glucose-induced thermogenesis (Astrup et al. 1989), so that about $33 \%$ of the thermic effect of feeding could be ascribed to changes in sympathetic nervous system (SNS) activity (Schwartz et al. 1988). Furthermore, it has been shown that plasma A levels increase up to values able to stimulate thermogenesis during physical activity (Cryer, 1980).

Maintenance of a reduced or elevated body weight is associated with compensatory changes in EE, which oppose the maintenance of a body weight different from the usual weight (Leibel et al. 1995). A decrease in RMR has been reported in obese patients during weight loss induced by a low-energy diet (LED) (Fricker et al. 1991). A reduced EE has been reported to persist in subjects who have maintained a reduced body weight for periods ranging from 6 months to more than 4 years (Leibel \& Hirsch, 1984) although other studies do not confirm this phenomenon (De Peuter et al. 1992). The reduction in RMR during a LED is accompanied by a concomitant reduction in FFM, as well as by a decrease in urinary noradrenalin (NA) excretion (Del Rio et al. 1989; Schwartz et al. 1990), and may account for the poor longterm efficacy of obesity treatment. Since the reduction in RMR during weight loss exceeds that accounted for by changes in body composition by $15 \%$ (Leibel et al. 1995), it is likely that factors other than FFM can account for the metabolic adaptation during food restriction in obesity.

Our study aims to establish if changes in the sympathoadrenal system activity, as inferred from an integrated measure such as $24 \mathrm{~h}$ urinary excretion of catecholamines, may play a role in the induction of RMR adaptation during dietary restriction in obese patients.

\section{Materials and methods}

Ninety-three female obese patients aged from 17 to 56 years, with no history of diabetes and systemic disease, were included in this study. However, only seventy-one patients (age 36 (SEM 1.6) years; height 160 (SEM 7) cm; BMI 40.3 (SEM 7) $\mathrm{kg} / \mathrm{m}^{2}$; waist : hip ratio $0 \cdot 84($ SEM $0 \cdot 1)$ ) completed the 3 -week period of the study.

The study protocol was approved by the local ethical committee. Each patient gave informed consent and was hospitalized at the Department of Internal Medicine of Modena, Italy, twice during the study. The protocol consisted of an initial $9 \mathrm{~d}$ period of a weight-maintenance diet $(60 \%$ of energy from carbohydrate, $25 \%$ from fat, $15 \%$ from protein) including $2 \mathrm{~d}$ of hospitalization for initial assessment which consisted of routine basal samples and a $24 \mathrm{~h}$ urine collection for determination of urea, creatinine, NA and A excretion. Measurement of body weight, waist: hip ratio, BMI $\left(\mathrm{kg} / \mathrm{m}^{2}\right)$, blood pressure, heart rate and electrocardiogram and RMR were carried out at the time of the admission to hospital.

In order to avoid the confounding effect of changes in SNS activity and metabolic rate during the menstrual cycle, the women started the weight-maintenance diet when in the early follicular phase (day 2 or 3 ).

After $9 \mathrm{~d}$ of the weight-maintenance diet all the patients started a $20 \mathrm{~d}$ period of a LED $(2930 \mathrm{~kJ} / \mathrm{d}(700 \mathrm{kcal} / \mathrm{d})$ with the following composition: $55 \%$ of energy as carbohydrate, $9.4 \%$ as lipid, $39 \%$ as protein), consumed at home. The collection of urine for urea, creatinine and catecholamines was repeated together with measurement of body composition and RMR at the end of the diet period (day 29-30) during a $2 \mathrm{~d}$ period of hospitalization (see Fig. 1).

Waist circumference was measured at the point halfway between the lower costal margin and the iliac crest; hip circumference was measured as the maximum circumference round the buttocks posteriorly and the symphysis pubis anteriorly. Urinary excretion of urea and creatinine was detected by spectrophotometric method (AU 5000 Analyzer System; Merck, Whitestation, NJ, USA).

The urine for measurement of free catecholamines was immediately acidified with $6 \mathrm{M}-\mathrm{HCl}$ and stored at $4^{\circ} \mathrm{C}$ until analysis. Urinary excretion rate of NA and A was measured in the $24 \mathrm{~h}$ urine specimens by reverse phase HPLC with electrochemical detection (Del Rio et al. 1992). FFM and fat mass (FM) were estimated by bioelectrical impedance (BIA 109; RJL Systems, Detroit, MI, USA) using a formula previously validated during a weight-reducing period (Kushner et al. 1990).

Resting EE was measured by indirect calorimetry (Deltatrac; Datex Instrumentarium, Helsinki, Finland), with a constant air flow of $40 \mathrm{l} / \mathrm{min}$ through a transparent canopy over the head of the subject in order to bring the expired gas to the metabolic monitor. The monitor measures the inspiratory $\mathrm{O}_{2}$ concentration and the difference between inspiratory and expiratory $\mathrm{O}_{2}$ concentration with a paramagnetic differential $\mathrm{O}_{2}$ sensor, and expired $\mathrm{CO}_{2}$ concentration continuously with an infrared sensor (the inspiratory $\mathrm{CO}_{2}$ level of the room air is measured every $2 \mathrm{~min}$ ). Prior to measurements, the sensors are calibrated with a gas mixture of known composition. $\mathrm{CO}_{2}$ output $\left(\mathrm{VCO}_{2}\right)$, as well as $\mathrm{O}_{2}$ uptake $\left(\mathrm{VO}_{2}\right)$, are calculated each min and converted to standard temperature and pressure, dry gas conditions. EE was

$\begin{array}{cccc}\text { Day } 1 & \text {.... } & \text { Day } 8 & \text { Day } 9 \\ & & 24 \text { h urinary } & \text { Bioimpedance } \\ & \text { urea, creatinine } & \text { Indirect calorimetry } \\ & & 24 \mathrm{~h} \text { urinary } \\ & & & \\ & & & \end{array}$

$\begin{array}{ccc}\text { Day } 10 & \text { Day } 30 & \text { Day } 31 \\ & & \text { Bioimpedance } \\ & \text { Indirect calorimetry } & 24 \mathrm{~h} \text { urinary } \\ & 24 \text { h urinary } & \text { catecholamines } \\ & \text { catecholamines } & \end{array}$

Fig. 1. Experimental design of the study. 
Table 1. Physical characteristics of the subjects during a weightmaintenance period and after consumption of a low-energy diet for 3 weeks $\dagger$

(Mean values with standard errors for seventy-one female subjects)

\begin{tabular}{|c|c|c|c|c|}
\hline & \multicolumn{2}{|c|}{$\begin{array}{l}\text { During weight } \\
\text { maintenance }\end{array}$} & \multicolumn{2}{|c|}{$\begin{array}{l}\text { End of low-energy- } \\
\text { diet period }\end{array}$} \\
\hline & Mean & SE & Mean & $\mathrm{SE}$ \\
\hline Weight (kg) & $105 \cdot 2$ & 2.6 & $102 \cdot 0^{\star \star \star}$ & $\overline{2.4}$ \\
\hline BMI $\left(\mathrm{kg} / \mathrm{m}^{2}\right)$ & $41 \cdot 1$ & 1.0 & $39 \cdot 8^{\star \star \star}$ & 0.9 \\
\hline Fat-free mass $(\mathrm{kg})$ & 58.4 & 1.2 & $56 \cdot 6^{\star \star \star}$ & 1.2 \\
\hline Fat mass $(\mathrm{kg})$ & $46 \cdot 4$ & 1.7 & $45 \cdot 3^{\star}$ & 1.6 \\
\hline
\end{tabular}

Mean values were significantly different from those during weight maintenance: ${ }^{\star} P<0.05,{ }^{* \star *} P<0.001$ (Student's $t$ test).

†The low-energy diet provided $2930 \mathrm{~kJ} / \mathrm{d}(700 \mathrm{kcal} / \mathrm{d})$ with $55 \%$ of energy as carbohydrate, $39 \%$ as protein and $9.4 \%$ as lipid.

calculated with the abbreviated Weir formula (Mansell \& Macdonald, 1990). The minute values of $\mathrm{VO}_{2}, \mathrm{VCO}_{2}, \mathrm{RER}$ and EE were sent to a microcomputer for later analysis.

Dietary compliance was ascertained by weekly ambulatory interviews and by a $3 \mathrm{~d}$ diet record in the middle of the $20 \mathrm{~d}$ LED period.

Data are presented as mean values with standard errors of the means. Student's $t$ test for paired data was used when appropriate. The relationship between different variables was evaluated using Pearson-product moment correlation and multivariate regression. In each regression model the variability in the dependent variable that is not accounted for by the predictor variables was calculated as described by Bogardus (1986). Stepwise multiple regression analysis with test of equality of regression lines across periods was also used (Jennrich, 1981).

\section{Results}

In the seventy-one subjects who completed the study the LED induced significant weight loss of 3.3 (SEM 0.4 ) kg $(P<0 \cdot 01$, Table 1$)$ and a reduction in BMI of $1 \cdot 3$ (SEM $0 \cdot 1)$ $\mathrm{kg} / \mathrm{m}^{2}(P<0.01$, Table 1$)$. The FFM decreased by 1.9 (SEM 0.7) $\mathrm{kg}$ during the LED $(P<0.01$, Table 1$)$ and the FM by $1 \cdot 2($ SEM 0.5$) \mathrm{kg}(P<0 \cdot 01$, Table 1$)$.
Urinary urea excretion did not show any significant modification during the observation period (714 (SEM 46) v. 633 (SEM 47) $\mathrm{mmol} / 24 \mathrm{~h}, \mathrm{NS}$ ), nor did urinary creatinine excretion (99.0 (SEM 8.8) v. 98.1 (SEM 7.0) $\mu \mathrm{mol} / 24 \mathrm{~h}, \mathrm{NS}$ ). NA excretion (24 h) was found to decrease during the LED (mean decrease 95 (SEM 22) nmol/24 h; $P<0 \cdot 001$ ), while mean $24 \mathrm{~h}$ A excretion did not change with LED (mean decrease 1.8 (SEM 2.9) nmol/24 h; NS) (Fig. 2).

The LED induced a significant decrease in RMR (7300 (SEM 218) v. 6831 (SEM 138) kJ/24h; $P<0.001$ ). At the beginning of the study significant correlations between RMR and body weight, FFM, FM and NA excretion were found (Table 2). A significant negative correlation was found between $24 \mathrm{~h}$ urine A excretion and body weight $(r-0 \cdot 37)$ but RMR was not related to A excretion (Table 2). The relative importance of the independent variables was assessed by multiple regression analysis, which demonstrated that RMR was significantly correlated with FFM, FM and NA excretion at the beginning of the study. FFM, FM and urinary NA excretion explained $88 \%$ of the variability in RMR before the diet. The residual standard deviation of the RMR after these covariates were accounted for was $607 \mathrm{~kJ} / \mathrm{d}$ (145 kcal/d).

At the end of the study period RMR was found to correlate significantly with the same variables in obese subjects (Table 2); no significant correlation was found between changes in NA and A excretion and changes in RMR induced by the LED ( $r 0.17$ and $r 0.09$ respectively; NS). Regression analysis indicated that $80 \%$ of the variance in RMR during the diet period was accounted for FFM while FM, NA, A, waist: hip ratio and age did not enter in the equation. The residual standard deviation of the RMR after this covariate was accounted for was $624 \mathrm{~kJ} / \mathrm{d}(149 \mathrm{kcal} / \mathrm{d})$. The relationship between RMR and FFM both before and after the diet is shown in Fig. 3. Slopes and intercept of the two regression lines did not differ before and after the diet ( $F$ 0.6; NS).

\section{Discussion}

RMR is influenced by factors such as age, sex, genetic traits, FFM and hormonal pattern (Ravussin \& Bogardus, 1992).

Table 2. Simple correlations between resting metabolic rate and variables assessed in subjects during a weight-maintenance period and after consumption of a low-energy diet for 3 weeks $\dagger$

(Correlation coefficients for seventy-one female subjects)

\begin{tabular}{|c|c|c|}
\hline & \multicolumn{2}{|c|}{ Correlation with RMR (r) } \\
\hline & $\begin{array}{l}\text { During weight } \\
\text { maintenance }\end{array}$ & $\begin{array}{c}\text { End of low-energy- } \\
\text { diet period }\end{array}$ \\
\hline Weight (kg) & $0.84^{\star * \star}$ & $0.86^{\star * *}$ \\
\hline Fat-free mass $(\mathrm{kg})$ & $0.78^{\star \star \star}$ & $0.75^{\star \star *}$ \\
\hline Fat mass $(\mathrm{kg})$ & $0.83^{\star \star \star}$ & $0.77^{\star \star \star}$ \\
\hline $24 \mathrm{~h}$ urinary noradrenalin (nmol/24 h) & $0.49^{\star}$ & $0.29^{\star}$ \\
\hline $24 \mathrm{~h}$ urinary adrenalin $(\mathrm{nmol} / 24 \mathrm{~h})$ & 0.10 & 0.19 \\
\hline Age (years) & 0.14 & $0 \cdot 15$ \\
\hline
\end{tabular}

RMR, resting metabolic rate.

Correlation was significant: ${ }^{*} P<0.05,{ }^{* \star \star} P<0.001$.

† The low-energy diet provided $2930 \mathrm{~kJ} / \mathrm{d}(700 \mathrm{kcal} / \mathrm{d})$ with $55 \%$ of energy as carbohydrate, $39 \%$ as protein and $9.4 \%$ as lipid. 

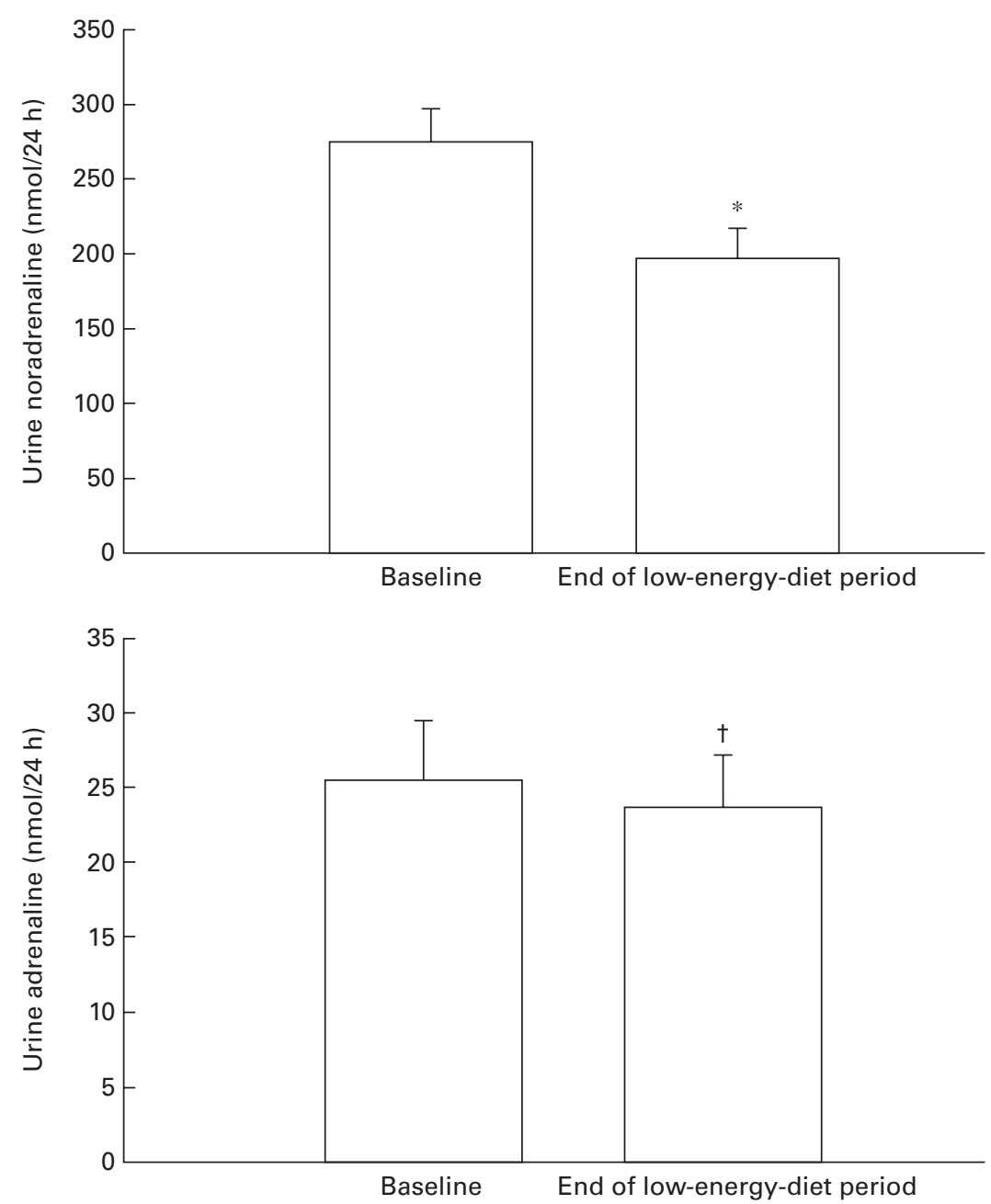

Fig. 2. Urinary excretion of noradrenalin and adrenalin during a weight-maintenance period and after consumption of a low-energy diet for 3 weeks in seventy-one obese subjects. The low-energy diet provided $2930 \mathrm{~kJ} / \mathrm{d}(700 \mathrm{kcal} / \mathrm{d})$ with $55 \%$ of energy as carbohydrate, $39 \%$ as protein and $9.4 \%$ as lipid. Values are means with standard errors of the means represented by vertical bars. Mean values were significantly different: ${ }^{*} P$ $<0.02$ (paired $t$ test). †Mean values were not significantly different (paired $t$ test).

A strict correlation exists between FFM and RMR in both sexes (Ferraro et al. 1992). Indeed, $82 \%$ of variability in RMR can be attributed to differences in FFM (Ravussin \& Bogardus, 1992). Therefore age, sex and FFM can explain the large part of individual variability of RMR although genetic factors and familial predisposition can account for a further $7 \%$. Among the factors influencing RMR the hormonal pattern, particularly the sympathoadrenal system, seems to play an important role (Saad et al. 1991).

The main aim of our study was to focus on the possible involvement of the sympathoadrenal system and FFM in determining metabolic adaptation during weight loss. Our patients lost less weight than expected from the estimated body-energy deficit over the 3 weeks; it is known that weight loss achieved during restricted dietary treatment varies between individuals (Astrup et al. 1995) and the dietary compliance may be lower when the patients are not hospitalized despite weekly controls being performed. Taking into account these considerations, we obtained a weight loss of about $1 \cdot 2-2 \cdot 0 \mathrm{~kg} /$ week which is comparable with that obtained in other studies (Ravussin et al. 1985; Stich et al. 1997).

During weight loss a concomitant decrease in FFM and a 10-28 \% reduction in RMR occurs (Davis et al. 1989; Elliot et al. 1989). This reduction is greater than expected for the loss of FFM alone (Fricker et al. 1991). Our data confirmed a highly significant correlation between FFM and RMR; RMR depends mainly on FFM both before and during diet therapy and the part of variance in RMR not attributable to FFM is similar to that described by Bogardus et al. (1986). NA excretion contributes significantly to energy expenditure before dietary restriction and this is in agreement with Jung et al. (1980) who reported that oral administration of propanolol led to a decrease of $8.6 \%$ in the RMR in obese women on a weight-maintenance diet. Likewise, clonidine administration is able to induce a $6 \%$ decrease in basal EE and to blunt the thermic effect of feeding in healthy subjects (Schwartz et al. 1988, 1990).

FM and the SNS may play a role in the modulation of RMR during period of restricted feeding (Ravussin et al. 


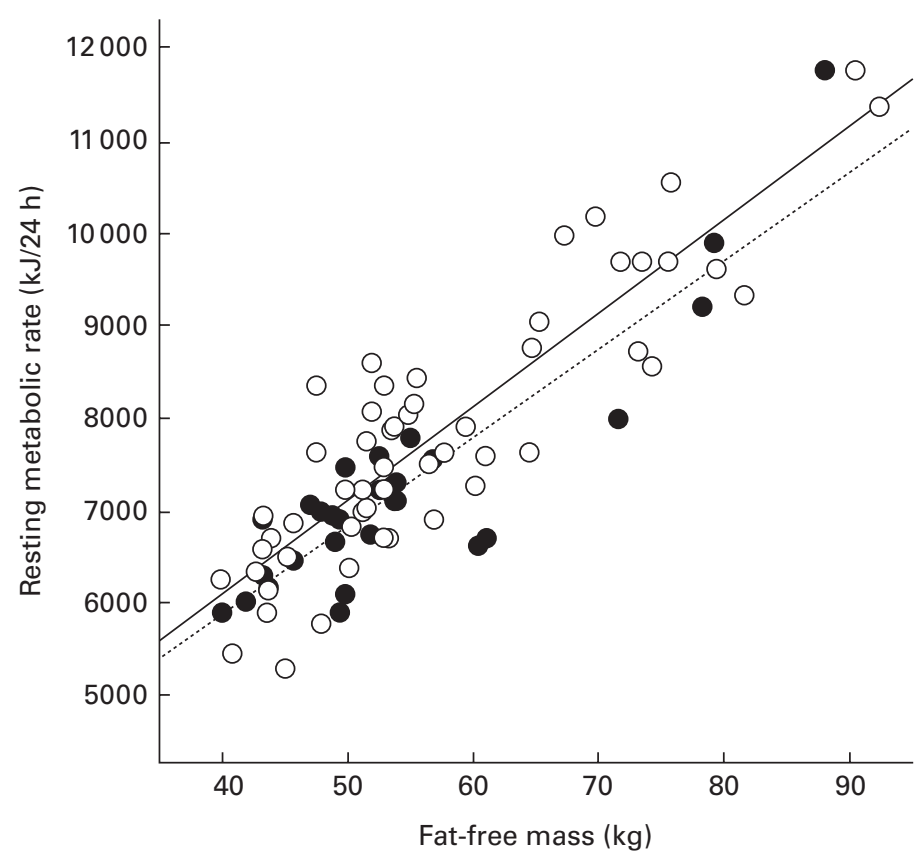

Fig. 3. Relationships between resting metabolic rate and fat-free mass in seventy-one obese subjects during a weight-maintenance period $\left((\bigcirc)\right.$ and $\left.(-), r^{2} 0.79\right)$ and after consumption of a low-energy diet for 3 weeks $\left((\bullet)\right.$ and $\left.(---), r^{2} 0.80\right)$. The low-energy diet provided $2930 \mathrm{~kJ} / \mathrm{d}$ $(700 \mathrm{kcal} / \mathrm{d})$ with $55 \%$ of energy as carbohydrate, $39 \%$ as protein and $9.4 \%$ as lipid.

1988; Saad et al. 1991). The reduction in FFM is said to explain most of the variability in RMR during the dietaryrestriction period in several reports (Ravussin et al. 1988; Leibel et al. 1995) and the resting plasma NA concentration decreases during energy restriction in normal weight and obese subjects (Berlin et al. 1990; Kempen et al. 1994), as a result of reductions in both the appearance and clearance rates of NA.

RMR correlated with $24 \mathrm{~h}$ urinary NA excretion in our patients at the end of the LED, but not after adjustment for FFM. This finding agrees with data previously obtained by Christin et al. (1993) where the correlations between RMR and both plasma NA appearance rate and $24 \mathrm{~h}$ urinary NA excretion disappeared after adjustment for differences in body size. The changes in SNS activity were not correlated with changes in RMR after adjusting for FFM variations, a finding that may be secondary to the very small variations in the variables estimated. Another possible explanation could be that the relative contribution of SNS to RMR during the period of reduced catecholamine secretion is less relevant than in basal conditions. We have recently obtained a significant effect of clonidine both on plasma NA and RMR (Valeriani et al. 1998), suggesting that only large reductions in SNS activity, as those induced by clonidine, are able to influence RMR.

Although $\mathrm{A}$ is the most active thermogenic hormone in man (Webber et al. 1994), we did not find any relationship between $24 \mathrm{~h}$ urinary A excretion and RMR in our patients. Since the threshold concentration of plasma A able to produce an effect on RMR ranges from 90 to $120 \mathrm{pg} / \mathrm{ml}$ (Sjostrom et al. 1983), values not usually found during supine, resting conditions, it seems likely that adrenomedullary activity is involved in the control of lipolysis and EE in a number of physiological situations but not during recumbent resting conditions. An inverse relationship between the percentage of body fat and the sympathoadrenal system has been demonstrated by several authors (Peterson et al. 1988; Del Rio et al. 1992). We also found a significant correlation between daily urinary NA excretion and FFM $(P<0.001)$, and a negative correlation between $\mathrm{A}$ and body weight $(P<0.05)$; this agrees with the hypothesis of enhanced SNS activity and reduced adrenomedullary secretion in obesity as previously suggested (Young \& Macdonald, 1992). Furthermore a decrease in NA excretion with no change in A excretion indicates a dissociation between adrenomedullary secretion and SNS activity in obese patients consuming a LED and fits well with other data regarding the autonomy of the two systems in response to stimuli (Del Rio et al. 1989; Young \& Macdonald, 1992). In conclusion, our results indicate that FFM is the major factor related to RMR both before and during weight loss induced by a LED in obese patients. The role of SNS activity as inferred by integrated measures is important in basal conditions in obese patients but not at the end of the dietary-restriction period.

\section{References}

Astrup A, Buemann B, Gluud C, Bennet P, Tjur T \& Christensen N (1995) Prognostic markers for diet-induced weight loss in obese women. International Journal of Obesity 19, 275-278.

Astrup A, Simonsen L, Bulow J, Madsen J \& Christensen NJ (1989) Adrenaline mediates facultative carbohydrate-induced 
thermogenesis in human skeletal muscle. American Journal of Physiology 257, E340-E345.

Berlin I, Berlan M, Crespo-Laumonnier B, Landault C, Payan C, Puech C \& Turpin G (1990) Alteration in beta-adrenergic sensitivity and platelet alpha 2-adrenoceptors in obese women: effect of exercise and caloric restriction. Clinical Science 78, 81-87.

Bogardus C, Lillioja S, Ravussin E, Abbott W, Zawadzki J, Young A, Knowler WC, Jacobowitz R \& Moll PP (1986) Familial dependency of resting metabolic rate. New England Journal of Medicine 315, 96-100.

Bouchard C, Tremblay A, Nadeau A, Després JP, Thériault G, Boulay MR, Lortie G, Leblanc C \& Fournier G (1989) Genetic effect in resting and exercise on metabolic rate. Metabolism 38, 364-370.

Bray GA, York DA \& Fisler JS (1989) Experimental obesity: a homeostatic failure due to defective nutrient stimulation of the sympathetic nervous system. Vitamins and Hormones 45, 1-125.

Christin L, O’Connell M, Bogardus C, Danforth E Jr \& Ravussin E (1993) Noradrenaline turnover and energy expenditure in Pima Indian and white men. Metabolism 42, 723-729.

Cryer PE (1980) Physiology and pathophysiology of the human sympathoadrenal neuroendocrine system. New England Journal of Medicine 303, 436-444.

Davis HJA, McLean Baird I \& Fowler J (1989) Metabolic response to low- and very-low calorie diets. American Journal of Clinical Nutrition 49, 745-751.

Del Rio G, Carani C, Bonati ME, Marrama P \& Della Casa L (1992) Sexual dimorphism of autonomic nervous system response to weight loss in obese patients. International Journal of Obesity 16, 897-903.

Del Rio G, Marrama P, Fiorani P \& Della Casa L (1989) Very low calorie diet induces opposite effects on sympathetic nervous system and adrenomedullary responses. International Journal of Obesity 13, Suppl. 2, 173-175.

De Peuter R, Withers RT, Brinkman M, Tomas FM \& Clark DG (1992) No differences in rates of energy expenditure between post-obese women and their matched, lean controls. International Journal of Obesity 16, 801-808.

Elliot DL, Goldberg L, Kvehl KS \& Bennett WM (1989) Sustained depression of the resting metabolic rate after massive weight loss. American Journal of Clinical Nutrition 49, 93-96.

Ferraro R, Lillioja S, Fontvieille AM, Rising R, Bogardus C \& Ravussin E (1992) Lower sedentary metabolic rate in women compared with men. Journal of Clinical Investigation 90, 780784.

Fricker J, Rozen R, Melchior JC \& Apfelbaum M (1991) Energy metabolism adaptation in obese adults on a very-low-caloriediet. American Journal of Clinical Nutrition 53, 826-830.

Jennrich RI (1981) Multiple linear regression. In BMDP Statistical Software, pp. 237-250 [F Dixon, editor]. Los Angeles, CA: University of California Press.

Jung RT, Shetty PS \& James WPT (1980) The effect of betaadrenergic blockade on metabolic rate and peripheral thyroid metabolism in obesity. European Journal of Clinical Investigation 10, 179-182.

Kempen KPG, Saris WHM, Seden JMG, Menheere PP, Blaak EE \& Baak MAV (1994) Effects of energy restriction on acute adrenoceptor and metabolic response to exercise in obese subjects. American Journal of Physiology 267, E694-E701. Kushner RF, Kunigk A, Alspaugh M, Andronis PT, Leitch CA \&
Schoeller DA (1990) Validation of bioelectrical-impedance analysis as a measurement of change in body composition in obesity. American Journal of Clinical Nutrition 52, 219-223.

Leibel RL \& Hirsch J (1984) Diminished energy requirements in reduced-obese patients. Metabolism 33, 164-170.

Leibel RL, Rosenbaum M \& Hirsch J (1995) Changes in energy expenditure resulting from altered body weight. New England Journal of Medicine 332, 622-628.

Mansell PI \& Macdonald IA (1990) Reappraisal of the Weir equation for calculation of metabolic rate. American Journal of Physiology 27, R1347-R1354.

Peterson HR, Rothschild M, Weinberg CR, Fell RD, McLeish LR \& Pfeifer MA (1988) Body fat and the activity of autonomic nervous system. New England Journal of Medicine 318, 10771080.

Ravussin E \& Bogardus C (1992) A brief overview of human energy metabolism and its relationship to essential obesity. American Journal of Clinical Nutrition 55, 242S-245S.

Ravussin E, Burnand B, Schutz Y \& Jequier E (1985) Energy expenditure before and during energy restriction in obese patients. American Journal of Clinical Nutrition 41, 753-759.

Ravussin E, Lillioja S, Knowler WC, Christin L, Freymond D, Abbott WGH, Boyce V, Howard BV \& Bogardus C (1988) Reduced rate of energy expenditure as a risk factor for body-weight gain. New England Journal Medicine 318, 467-472.

Saad MF, Alger SA, Zurlo F, Young JB, Bogardus C \& Ravussin E (1991) Ethnic differences in sympathetic nervous systemmediated energy expenditure. American Journal of Physiology 261, E789-E794.

Schwartz RS, Jaeger LF \& Veith RC (1988) Effect of clonidine on the thermic effect of feeding in humans. American Journal of Physiology 54, R90-R94.

Schwartz RS, Jaeger LF \& Veith RC (1990) The effect of diet on exercise on plasma noradrenaline kinetics in moderately obese young men. International Journal of Obesity 14, 1-11.

Sjostrom L, Schutz Y, Gudinchet F, Hegnell L, Pittet PhG \& Jequier E (1983) Adrenaline sensitivity with respect to metabolic rate and other variables in women. American Journal of Physiology 245, E431-E442.

Stich V, Harant I, De Glisezinski I, Crampes F, Berlan M, Kunesova M, Hainer V, Dauzats M, Riviere D, Garrigues M, Holm C, Lafontan M \& Langin D (1997) Adipose tissue lipolysis and hormone-sensitive lipase expression during verylow-calorie diet in obese female identical twins. Journal of Clinical Endocrinology and Metabolism 82, 739-744.

Valeriani L, Bondi M, Menozzi R, Tavernari V, Sinisi R, Bertouli M, Velardo A \& Del Rio G (1998) Thermogenetic cardiovascular and catecholaminergic response to clonidine. International Journal of Obesity 22, Suppl. 3, 353 Abstr.

Webber J, Donaldson M, Allison SP, Fukagawa NK \& Macdonald IA (1994) The effects of weight loss in obese subjects on the thermogenic, metabolic and haemodynamic responses to the glucose clamp. International Journal of Obesity 18, 725-730.

Webber J \& Macdonald IA (1993) Metabolic actions of catecholamines in man. In Balliere's Endocrinology and Metabolism, pp. 393-413 [WB Saunders, editor]. Philadelphia, PA: Bouloux.

Young JB \& Macdonald IA (1992) Sympathoadrenal activity in human obesity. Heterogeneity of findings since 1980. International Journal of Obesity 16, 959-967. 